Revue de sciences sociales sur les arts, la culture et les idées

\title{
Pour une sociologie historique des plaisirs populaires
}

For a Historical Sociology of Popular Pleasures

Por una sociología histórica de los placeres populares

\section{Philippe Gaboriau}

\section{(2) OpenEdition \\ Journals}

Édition électronique

URL : http://journals.openedition.org/bssg/135

DOI : $10.4000 /$ bssg. 135

ISSN : 2490-9424

Éditeur

Presses universitaires de Vincennes

Référence électronique

Philippe Gaboriau, "Pour une sociologie historique des plaisirs populaires », Biens Symboliques /

Symbolic Goods [En ligne], 1 | 2017, mis en ligne le 15 octobre 2017, consulté le 04 mars 2021. URL

http://journals.openedition.org/bssg/135; DOI : https://doi.org/10.4000/bssg.135 

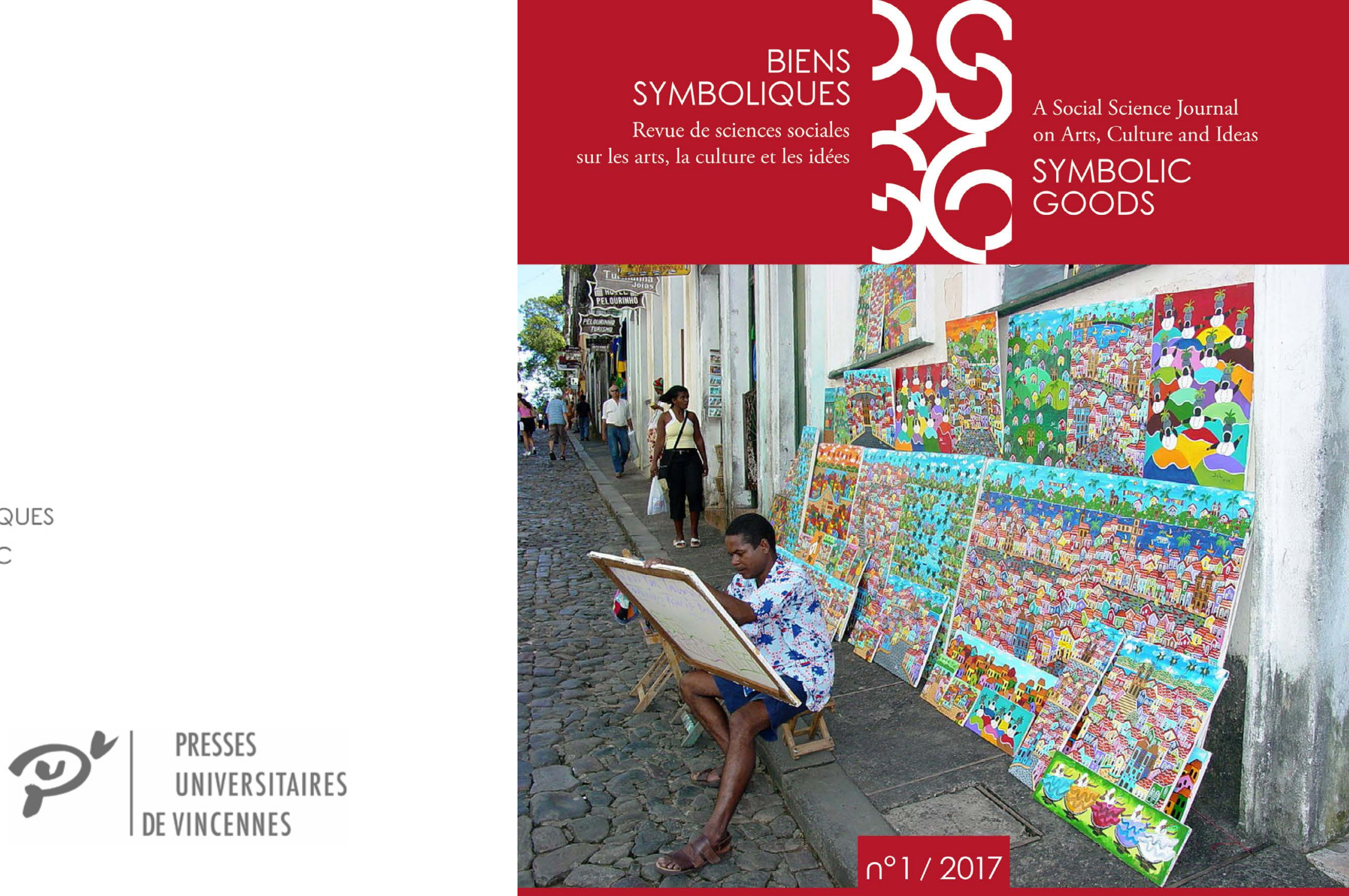

\section{Artistes ordinaires \\ Ordinary Artists}




\title{
Pour une sociologie historique des plaisirs populaires
}

\author{
Philippe Gaboriau
}

Le Savant et le Populaire ? Maintenant ? C'est, pour moi, un souvenir des années 1980 mais c'est aussi un livre bien présent en cette année 2017 : un ouvrage clef, je crois, de ma bibliothèque.

\section{1.}

C'est, tout d'abord, un souvenir du milieu des années 1980. À la Vieille Charité. Dans le quartier du Panier. En plein centre ville. C'est l'été sur Marseille. La canicule. Je suis jeune chercheur dans le nouveau centre de recherche EHESS et CNRS que dirige Jean-Claude Passeron. Nous venons de sortir le premier numéro de la revue Enquête : "À propos des cultures populaires », un débat de Claude Grignon et Jean-Claude Passeron (une des premières formes du texte qui deviendra Le Savant et le Populaire en 1989) et nous voilà submergés de demandes d'achat. Des centaines et des centaines de demandes. Paul Veyne vient d'écrire un article élogieux (intéressant et amusant, comme il en a le secret) dans Le Nouvel Observateur daté du 19-25 juillet 1985. Titre de cet article : «Doctor Miserabilis et Mister Populo. Quand la sociologie cesse d'être puissante et bête comme du Zola ». En toute urgence, en cette fin du mois de juillet, à Marseille, nous devons faire plusieurs nouvelles éditions du numéro 1 de la revue Enquête et organiser, nous-mêmes, l'envoi du texte aux particuliers et aux libraires qui le demandent. La Fnac
Montparnasse, de la rue de Rennes, était très solliciteuse et je me souviens des lourds paquets de livres que nous portions à la poste voisine, plusieurs fois par semaine au début du mois d'août de cette année 1985.

L'article de Paul Veyne commençait ainsi :

Chic, enfin un livre qui va déplaire à tout le monde ! Et donc un livre qui dit vrai. Chacun sait, a su ou saura qu'il n'existe de vérité que des historiens ou des sociologues (c'est la même race), et plus généralement des interprètes: il n'y a pas de vérité des choses. Des vérités frustrantes nous viennent donc du sociologue Claude Grignon, subtil interprète de la culture populaire ; et de son complice JeanClaude Passeron, qui a été co-auteur avec Bourdieu de La Reproduction et de ces Héritiers qui furent le premier détonateur de Mai 68. Seulement, ou j'avais mal compris $L a$ Reproduction ou Passeron a changé1.

Dans les années 1980, Claude Grignon et Jean-Claude Passeron sont en train - chacun à leur manière - de prendre leurs distances vis-à-vis de Pierre Bourdieu, maintenant au Collège de France. Claude Grignon a quitté la revue Actes

1 Paul Veyne (1985). « Doctor Miserabilis et Mister Populo. Quand la sociologie cesse d'être puissante et bête comme du Zola ». Le Nouvel Observateur, 19-25 juillet : 62-63. Voir également Lucien Malson (1984). «Culture... et cultures populaires ». Le Monde, 26 avril, et Arlette Farge (1990). « L'oubli du peuple ». Libération, 18 janvier. 
de la recherche - dont il était une des chevilles ouvrières - et le centre de recherche de Pierre Bourdieu, et Jean-Claude Passeron, après avoir écrit sa thèse d'État en 1980, est nommé, en 1982, directeur d'études à l'EHESS. II a 52 ans. II publie régulièrement des articles d'épistémologie critiquant les positions de Pierre Bourdieu - articles qui formeront le cœur du livre Le Raisonnement sociologique publié en 1991 - et part, en 1983, à Marseille où il crée le Cercom (Centre d'enquêtes et de recherches sur la culture, la communication, les modes de vie et la socialisation) et l'Imerec (Institut méditerranéen de recherche et de création), «projet ambitieux » qu'il présente ainsi dans le journal Impressions du Sud de 1986 :

À Marseille, ma conviction est qu'on peut faire ce que j'appelle les trois D : Décentralisation, Déconcentration et Décloisonnement. Déconcentrer, c'est travailler à sortir de la logique des vastes institutions qui tendent à croître en s'alourdissant de divers phénomènes bureaucratiques. Il est difficile, pour ne pas dire impossible, de concentrer dans les mêmes institutions les nouvelles synergies (par exemple, entre les chercheurs et les artistes qui travaillent dans des univers étanches), il faut créer des instruments ad hoc, ne pas tout concentrer dans de grandes machines qui ne sont pas faites pour permettre les percées, les écarts à la norme ${ }^{2}$.

Depuis les années 1970, Jean-Claude Passeron s'intéresse aux cultures populaires. En 1970, il a traduit - en collaboration avec Françoise et Jean-Claude Garcia - le livre La Culture du pauvre de Richard Hoggart (1970), il en a aussi écrit la préface et la présentation française. Au même moment, il

2 Propos recueillis par Alain Paire. fonde, avec Michel Verret, le Lersco (Laboratoire d'études et de recherches sur la classe ouvrière) à Nantes. Dans les années 1990, Passeron organise, à Marseille, une journée autour de Richard Hoggart (physiquement présent) à la Vieille Charité. Les interventions de cette journée, complétées par plusieurs articles, donnent lieu à une publication (Passeron 1999). Durant l'année universitaire 1989-1990, Jean-Claude Passeron propose, à l'EHESS de Marseille, un séminaire qui s'intitule "Sociologie et sémiologie de réception des œuvres ». II a alors une proximité théorique forte avec l'École de Constance (en particulier, les travaux de Jauss autour de la notion d'« horizon d'attente »). En 1989, Claude Grignon effectue, lui, la traduction et prépare la présentation du deuxième livre de Richard Hoggart à paraître en France, 33 Newport street (Hoggart 1991).

\section{2.}

Maintenant, Le Savant et le Populaire - dans sa forme définitive de 1989 - est devenu un des ouvrages essentiels de ma bibliothèque. C'est, pour moi, un outil épistémologique de première importance. Un instrument de travail et de réflexion qui ressemble au Métier de sociologue (Bourdieu et al. 1968). Les deux livres sont d'ailleurs construits de la même manière : des propos savants en première partie, un recueil de textes clés en deuxième partie ${ }^{3}$.

3 En 1988, vingt ans après la première publication, Pierre Bourdieu présentait Le Métier de sociologue comme "un texte programmatique " mais aussi comme « un livre de professeur » : «Au fond, Le Métier de sociologue reste un livre de professeur. D'ailleurs, il y a beaucoup de choses négatives et ça, c'est typiquement un truc de professeur... Ne faites pas ci, ne faites pas ça... 
Le Savant et le Populaire est une porte d'entrée intéressante qui permet d'aller et de venir entre Pierre Bourdieu et Richard Hoggart, de « godiller » (pour reprendre une expression utilisée par Grignon et Passeron) entre deux types d'enquêtes incarnées par deux livres emblématiques : La Distinction (Bourdieu 1979) et La Culture du pauvre (Hoggart 1970) ${ }^{4}$. Le Savant et le Populaire valorise la consommation, la réception. II éclaire, de manière remarquable, la notion de " consommation nonchalante », d'« attention oblique » développée par Richard Hoggart. J'aime relire la page 81 avec ces propos de Jean-Claude Passeron :

C'est l'oubli de la domination, non la résistance à la domination, qui ménage aux classes populaires le lieu privilégié de leurs activités culturelles les moins marquées par les effets symboliques de la domination. Si la parenthèse du dimanche, si les activités insulaires de l'aménagement de l'habitat ou l'activisme décontracté de la sociabilité entre pairs permettent le mieux de saisir dans sa cohérence symbolique l'univers culturel de la vie ouvrière et citadine [...], c'est que ces conditions ménagent un univers soustrait à la confrontation, des moments de répit, des lieux d'altérité. Ce n'est pas un hasard si la riche moisson

C'est plein de mises en garde [...]. II répète sans cesse qu'il faut construire, mais sans jamais montrer pratiquement comment on construit. Je pense que c'est un livre qui a fait aussi du mal. II a réveillé les gens, mais il a été tout de suite utilisé dans le sens théoréticiste. Parmi les manières de ne pas faire de la sociologie - il y en a beaucoup -, il y en a une qui consiste à se gargariser de grands mots et à sacrifier indéfiniment aux "préalables épistémologiques". Le métier se transmet en grande partie en pratique, et pour être capable de le transmettre, il faut l'avoir très profondément intériorisé » (Bourdieu 1988 : $\mathrm{XV})$.

4 Cf., sur ce thème, le stimulant article de Dominique Pasquier (2005). de « valeurs » et de « traits » populaires qu'engrange la description ethnographique de Hoggart s'est effectuée par une prospection du monde local ou familial de « l'entre-soi » populaire. Que ses expressions de la culture populaire « au repos » et « à distance » ne représentent pas un danger politique ou idéologique pour les classes dominantes est une autre histoire, qui ne saurait se substituer à la tâche de description qui incombe à la sociologie.

Le livre complexifie la dialectique dominé-dominant. Il lui donne une ouverture qui me semble anarchisante. Néo-wéberienne, dirait Passeron. Une nouvelle fenêtre, optimiste, sur l'avenir. Pas seulement pour les milieux dits « populaires » mais pour tous les milieux, les moments, les espaces dominés.

Par ce texte, nous entrons à l'intérieur d'un débat théorique qui valorise la fécondité du principe de la double lecture et de la double enquête. Les cultures populaires/dominées appellent deux lectures. Les groupes dominés ont une culture. Une culture autonome. Cette culture (qui semble autonome) est une culture dominée. Les deux grilles de lecture et d'interprétation sont contradictoires. L'une et l'autre sont insuffisantes, et l'une et l'autre sont « incontournables ». Claude Grignon prend des exemples concrets (125) :

Le jardinage ou le bricolage domestique demandent à être décrits à la fois comme une détente et comme une corvée, comme un plaisir désintéressé, pour lequel on ne compte ni son temps, ni sa peine, ni même son argent, et comme un calcul, comme ce dont les classes dominantes sont dispensées et comme ce dont elles sont exclues, etc. [...] Ainsi la culture technique constitue à la fois un acquis, une «propriété » conquise par la classe ouvrière et une forme de culture dominée qui, outre qu'elle sert à la sélection 
de l'élite ouvrière, peut induire une forme particulière de reconnaissance des hiérarchies culturelles dominantes.

Le Savant et le Populaire est, me semble-t-il, à historiser, à contextualiser et à rapprocher de deux ensembles de recherches qui ont bouleversés les sciences sociales à la fin des années 1980 et au début des années 1990 : l'approche néo-wéberienne de Jean-Claude Passeron et la microhistoire italienne, revisitée par Jacques Revel et l'école des Annales (Collectif 1988). Et les livres suivants, que j'aime consulter et relire, sont à côté les uns des autres dans l'étagère «Passeron » de ma bibliothèque, à côté du Savant et du Populaire et des ouvrages cités plus haut. J'aime, par exemple, rapprocher les livres « néo-wéberiens » de JeanClaude Passeron avec ceux de ses deux amis, Paul Veyne et Michel Foucault (Passeron 1991, 2006 ; Veyne 1971, 2008 ; Foucault 1994, 1973), mais aussi avec Olivier de Sardan 2008, Fabiani 2001, Revel 1996, Levi 1989 ou Ginzburg 1980.

\section{3.}

Je considère donc que Le Savant et le Populaire est un des livres les plus importants de ma bibliothèque avec, peutêtre, L'CEuvre de François Rabelais et la culture populaire au Moyen Âge et sous la Renaissance (1970) de Mikhaïl Bakhtine, et La Société des individus (1991) de Norbert Elias. Le livre de Claude Grignon et Jean-Claude Passeron m'a aidé à développer mes enquêtes sur l'histoire sociale du vélo et des spectacles sportifs comme le Tour de France cycliste (Gaboriau 1995, 2003). II m'aide encore, au quotidien, à mettre en forme la sociologie historique des plaisirs populaires sur laquelle, en ce moment, j'écris mes prochains livres. Après avoir «godillé » de longues années sur deux terrains contrastés qui sont au cœur de ces livres : un village industriel du Choletais (dans l'Ouest de la France) et la ville de Marseille ${ }^{5}$.

La France est, en effet, une forme civilisatrice originale. C'est aussi un espace multiculturel marqué par trois faits historiques $^{6}: 1$. une centralité parisienne forte qui a accéléré la diffusion des valeurs lettrées ; 2 . le refus par les classes populaires rurales d'une industrialisation qui remettait en cause leur mode de vie et leur raison d'être ; 3 . une arrivée forte durant le $\mathrm{XIX}$ et le $\mathrm{XX}^{\mathrm{e}}$ siècles d'immigrants - souvent issus des ex-colonies françaises - qui sont apparus comme une solution à l'impossible industrialisation du pays. Pierre Bourdieu et Norbert Elias, chacun à leur manière, ont fort bien enquêté sur le point 1. Claude Grignon et Jean-Claude Passeron nous donnent les outils (des clefs qui ouvrent quelques portes et fenêtres) pour mieux regarder les points 2 et 3 et comprendre l'énigmatique « matière noire » de la sociologie historique des cultures françaises.

Philippe Gaboriau Centre Norbert Elias, EHESS, Marseille http://centre-norbert-elias.ehess.fr/

5 À paraître : Philippe Gaboriau, Plaisirs d'automne. L'univers d'une ouvrière de la chaussure choletaise dans la France rurale de la fin du vingtième siècle et Sept promenades socio-historiques dans l'originalité du monde marseillais.

$6 \quad C f$., sur ce thème, l'ensemble des travaux de l'historien Gérard Noiriel, et en particulier Noiriel 1988. 


\section{Références bibliographiques}

Aron Raymond (1983). Mémoires. Paris, Julliard.

BAKHTINE Mikhaïl (1970). L'CEuvre de François Rabelais et la culture populaire au Moyen Âge et sous la Renaissance. Paris, Gallimard.

BECKER Howard (1988). Les Mondes de l'art. Traduit de l'anglais par Jeanne Bouniort. Paris, Flammarion.

Bellavance Guy, Boivin Micheline, Santerre Lise (dir.) (2000). Démocratisation de la culture ou démocratie culturelle ? Deux logiques d'action publique. Québec, Éditions de l'IQRC.

Bols Géraldine (2008). "Le consentement à la domination littéraire. Degrés et diversité de ses formes chez les écrivains "les moins reconnus" de l'univers littéraire ». Tracés, $14:$ 55-76.

BouRdieu Pierre (1979). La Distinction. Critique sociale du jugement. Paris, Minuit.

Bourdieu Pierre (1984). Questions de sociologie. Paris, Minuit.

BOURDIEU Pierre (1988). «Entretien recueilli par Beate Krais ». In BOURDIEU Pierre, Chamboredon Jean-Claude, Passeron Jean-Claude, Le Métier de sociologue. Préalables épistémologiques. Paris, Éditions de l'EHESS (cinquième édition)

BouRdieu Pierre (1989). La Noblesse d'État. Paris, Minuit.

BOURDIEU Pierre (1993). «Les contradictions de I'héritage ». In Bourdieu Pierre (dir.), La Misère du monde. Paris, Seuil : 711-718.

BOURDIEU Pierre (1998) [1992]. Les Règles de l'art. Genèse et structure du champ littéraire. Paris, Seuil.

BouRDIEU Pierre (1998). La Domination masculine. Paris, Seuil.

Bourdieu Pierre (2003) [1997]. Méditations pascaliennes. Paris, Seuil.

BourdieU Pierre, Chamboredon Jean-Claude, PASSERON Jean-Claude (1968). Le Métier de sociologue. Paris, Mouton.

BourdieU Pierre \& PASSERON Jean-Claude (1964). Les Héritiers. Les étudiants et la culture. Paris, Minuit.

BOURDIEU Pierre \& PASSERON Jean-Claude (1970). La Reproduction. Éléments pour une théorie du système d'enseignement. Paris, Minuit. BOURDIEU Pierre \& WACQUANT LOÏc (2014). Invitation à la sociologie réflexive. Paris, Seuil.
BOUTIER Jean (2008). "Quelques réflexions rétrospectives sur les histoires de la "culture populaire" ». Journée d'étude « Le Savant et le Populaire, 1989-2008. Retour sur un débat en suspens ». SHADYC, EHESS Marseille (non publié).

BouVERESSE Jacques (2008). « Le besoin de croyance et le besoin de vérité ». Agone, 38-39: 281-306.

BuRKe Peter (1978). Popular Culture in Early Modern Europe. Londres Temple Smith.

Buscatto Marie (2014). Sociologies du genre. Paris, Armand Colin.

BusıNo Giovanni (2006). «Entretien avec Dominique Schnapper ». Revue européenne des sciences sociales, XLIV(135). [En ligne] http://ress. revues.org/271 [consulté le 12 octobre 2016].

CAsanova Pascale (2008) [1999]. La République mondiale des lettres. Paris, Seuil.

ChAPOULIE Jean-Michel (1991). « La seconde fondation de la sociologie française, les États-Unis et la classe ouvrière ». Revue française de sociologie 32(3) : 321-364.

CHARTIER Roger (2001). « Culture écrite et littérature à l'âge moderne ». Annales. Histoire, Sciences sociales, 56(4) : 783-802

COHEN Déborah (2010). La Nature du peuple. Les formes de l'imaginaire social (XVIII $/ X X I^{e}$ siècles). Seyssel, Champ Vallon.

COLLECTIF (1988). « Histoire et sciences sociales. Un tournant critique ? ». Annales ESC, 2 : 291-293.

Collectif Révoltes logiques (1984). L'Empire du sociologue. Paris, La Découverte.

Collovald Annie (1988). « Identité(s) stratégiques(s) », Actes de la recherche en sciences sociales, $73: 29-40$.

Connell Raewyn (1995). Masculinities. Cambridge, Polity Press.

CoRNU Tanguy (2008). « L'ambiguïté du concept de domination symbolique dans Le Savant et le Populaire ». Journée d'étude « Le Savant et le Populaire, 1989-2008. Retour sur un débat en suspens ». SHADYC, EHESS Marseille (non publié).

Coulangeon Philippe \& Duval Julien (2013). Trente ans après La Distinction de Pierre Bourdieu. Paris, La Découverte.

Coulangeon, Philippe \& Duval Julien (2013). « Introduction ». In EID. (dir.), Trente ans après La Distinction de Pierre Bourdieu. Paris, La Découverte. 
Daudet Alphonse (1868). Le Petit Chose. Paris, Pierre-Jules Hetzel.

Debeauvals Michel (1976). L'Université ouverte : les dossiers de Vincennes. Grenoble, Presses Universitaires de Grenoble.

Dragomir Lucia (2011). « L'Union des écrivains. Un modèle institutionnel et ses limites ». Vingtième siècle, $109:$ 59-70.

Ducournau Claire (2017). "Les deux (ou trois) carrières de Richard Hoggart. De la fondation des cultural studies aux appropriations de la sociologie française ". Revue d'anthropologie des connaissances, 11(3) : 263-282.

Dumont Fabienne \& SofiO Séverine (2007). " Esquisse d'une épistémologie de la théorisation féministe en art ». Cahiers du genre, 43 : 17-43.

DUVAL Julien (2010). "Distinction studies ". Actes de la recherche en sciences sociales, 181-182: 146-156.

ELIAS Norbert (1991). La Société des individus. Traduit de l'allemand par Jeanna Etoré. Paris, Fayard.

FABIANI Jean-Louis (dir.) (2001). Le Goût de l'enquête. Pour Jean-Claude Passeron. Paris, L'Harmattan.

FossÉ-PolıAK Claude (2006). Aux frontières du champ littéraire. Sociologie des écrivains amateurs. Paris, Économica.

FouCAULt Michel (1973). Moi, Pierre Rivière ayant égorgé ma mère, ma sœur et mon frère... Paris, Gallimard/Julliard.

FouCAuLt Michel (1994). Dits et écrits, t. 1 et 2. Paris, Gallimard.

GaboriAu Philippe (1995). Le Tour de France et le vélo. Histoire sociale d'une épopée contemporaine. Paris, L'Harmattan.

GaboriaU Philippe (2003). Les Spectacles sportifs. Grandeurs et décadences. Paris, L'Harmattan.

GinZBURG Carlo (1980) [1976]. Le Fromage et les vers. L'univers d'un meunier du XVI siècle [Il formaggio e i vermi. II cosmo di un mugnaio del Cinquecento, Turin, Einaudi]. Traduit de l'italien par Monique Aymard. Paris, Flammarion.

Grenier Jean-Yves, Grignon Claude, Menger Pierre-Michel (dir.) (2001). Le Modèle et le récit. Paris, Maison des Sciences de l'Homme.

GrignON Claude (1996). « Le savant et le lettré, ou l'examen d'une désillusion », Revue européenne des sciences sociales, 103 : 81-98.
GriGNON Claude (2001). « La formalisation et les sciences du récit, le cas de la sociologie ". In Grenier Jean-Yves, Grignon Claude, Menger Pierre-Michel (dir.), Le Modèle et le récit. Paris, Maison des Sciences de l'Homme : 7-43.

GriGnON Claude \& Kordon Claude (dir.) (2009). Sciences de l'homme et sciences de la nature, essais d'épistémologie comparée. Paris, Maison des Sciences de l'Homme.

GRIGNON Claude \& PASSERON Jean-Claude (1982). Sociologie de la culture et sociologie des cultures populaires. Paris, Documents du GIDES, 4

Grignon Claude \& PAsseron Jean-Claude (1985). Enquête. Cahiers du CERCOM, 1 (« À propos des cultures populaires »). [En ligne] https:// enquete.reveues.org/2 [consulté le 26 juin 2017].

GRIGNON Claude \& PASSERON Jean-Claude (2015) [1989]. Le Savant et le Populaire. Misérabilisme et populisme en sociologie et en littérature. Paris, Seuil, «Points 》 [1 $1^{\text {re }}$ éd. Gallimard/Seuil, « Hautes études 》]. En espagnol : Grignon Claude \& PASSERON Jean-Claude (1991). Lo culto y lo popular : miserabilismo y populismo en sociologia y en literatura. Traduction de María Sonderéguer. Buenos Aires, Ediciones Nueva Vision; GrignON Claude \& PASSERON Jean-Claude (1992). Lo culto y lo popular : miserabilismo y populismo en sociologia y en literatura. Traduction de Fernando Alvarez-Uria et Julia Varela. Madrid, Las Ediciones de La Piqueta.

Grignon Claude, Collovald Annie, Pudal Bernard, Sawickı Frédéric (1991). « Un savant et le populaire. Entretien avec Claude Grignon ». Politix, $13:$ 35-42.

GRUEL Louis (2004). La Rébellion de 68. Une relecture sociologique. Rennes, Presses Universitaires de Rennes.

GUILLAUMIN Colette (2002) [1972]. L'Idéologie raciste. Paris, Gallimard.

HaLL Stuart \& JeFFERSON Tony (dir.) (1976). Resistance through Rituals : Youth Subcultures in Post-War Britain. Londres, Hutchinson.

Hammou Karim (2008). « Penser le pouvoir avec Le Savant et le Populaire». Journée d'étude « Le Savant et le Populaire, 1989-2008. Retour sur un débat en suspens ». SHADYC, EHESS Marseille (non publié).

HEINICH Nathalie (2000) [1991]. Etre écrivain. Paris, La Découverte.

Hoggart Richard (1970a). La Culture du pauvre. Étude sur le style de vie des classes populaires en Angleterre. Traduit de l'anglais par Françoise 
Garcia, Jean-Claude Garcia et Jean-Claude Passeron, présentation et index de Jean-Claude Passeron (titre original The Uses of Literacy : Aspects of Working Class Life). Paris, Minuit.

HogGART Richard (1970b). Speaking to Each Other, vol. 1. Londres, Chatto et Windus.

Hoggart Richard (2013) [1991]. 33 Newport Street. Autobiographie d'un intellectuel issu des classes populaires anglaises. Traduit de l'anglais par Christiane Grignon \& Claude Grignon avec la collaboration de Christopher Todd, présentation de Claude Grignon. Paris, Seuil, «Points »

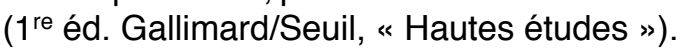

KALIFA Dominique (2005). "Les historiens français et le "populaire" ». Hermès, $42:$ 54-59.

KRÉFA Abir (2013). " La quête de l'autonomie littéraire en contexte autoritaire : le cas des écrivains tunisiens ». Sociologie, $4: 395-411$.

KRÉFA Abir (2013). Activités littéraires et rapports sociaux de sexe : le cas des écrivains tunisiens (thèse de doctorat en sociologie). Lyon, Université Lyon 2.

KRÉFA Abir (2014). « Entre injonctions à dire et à taire le corps : les voies étroites de la reconnaissance littéraire pour les écrivaines tunisiennes ». Ethnologie française, 44(4) : 631-642.

LAGRAVE Rose-Marie (1980). Le Village romanesque. Le Paradou, Actes Sud, «Espace-temps ».

LAGRAVE Rose-Marie (1988). "Mensonge romanesque et vérité des romanciers. Une relecture du Village Romanesque ». Etudes Rurales, $109: 55-73$.

LAGRAVE Rose-Marie (2009). "Filiations intellectuelles et espérance sociale. Figure et œuvre de Placide Rambaud ». Études rurales, 183 : 51-66.

LaGrave Rose-Marie (2010). "Se ressaisir ». Genre, Sexualité \& Société, $4: 1$-17. [En ligne] http://gss.revues.org

LAHIRE Bernard (2004). La Culture des individus : dissonances culturelles et distinction de soi. Paris, La Découverte.

LAHIRE Bernard (2008). La Raison scolaire. École et pratiques d'écriture, entre savoir et pouvoir. Rennes, Presses Universitaires de Rennes.

Lahire Bernard (2012). Monde pluriel. Penser l'unité des sciences sociales. Paris, La Découverte.
LAMONT Michèle (1995). La Morale et l'argent : les valeurs des cadres en France et aux États-Unis. Paris, Métailié.

LAMONT Michèle (2013). " En quoi Bourdieu a-t-il été utile à notre réflexion ? Le cas des États-Unis ». In CoulANGEON Philippe \& DuvaL Julien (dir.), Trente ans après La Distinction de Pierre Bourdieu. Paris, La Découverte : 59-68.

LevI Giovanni (1989). Le Pouvoir au village. Histoire d'un exorciste dans le Piémont du XVII siècle. Paris, Gallimard.

LINHART Robert (1981). L'Etabli. Paris, Minuit.

MACKENZIE Caroline (2012). " Agency, un mot, un engagement 》. Rives méditerranéennes, 41(1). [En ligne] http://rives.revues.org/4139 [consulté le 11 mars 2017].

MATHIEU Nicole-Claude (1991). L'Anatomie politique. Paris, Côté-Femmes. MAUGER Gérard (1991). «Enquêter en milieu populaire ». Genèses, 6 : 125-143.

MAUGER Gérard (2005). " Un apprentissage tardif du métier de sociologue ». In MAUGER Gérard (dir.), Rencontres avec Pierre Bourdieu. Bellecombe-en-Bauges, Le Croquant : 239-257.

MAUGER Gérard (2006a). « Sur la violence symbolique ». In MüLLER HansPeter \& Sintomer Yves (dir.). Pierre Bourdieu, théorie et pratique. Paris, La Découverte : 84-100.

MAUGER Gérard (2006b). Les Bandes, le milieu et la bohème populaire. Études de sociologie de la déviance des jeunes des classes populaires (1975-2005). Paris, Belin.

MAUgeR Gérard (2013). " Bourdieu et les classes populaires. L'ambivalence des cultures dominées ». In CoulangeOn Philippe \& DUVAL Julien (dir.), Trente ans après La Distinction de Pierre Bourdieu. Paris, La Découverte : 243-254.

MAUGER Gérard (2014). « Domination ». Le Lexique socius. [En ligne] http:// ressources-socius.info/index.php/lexique/21-lexique/154-domination [consulté le 14 janvier 2017].

MAUGer Gérard \& Fossé Claude (1977). La Vie buissonnière. Marginalité petite-bourgeoise et marginalité populaire. Paris, Maspero.

MAUGER Gérard \& Fossé-PolıAK Claude (1985). "Choix politiques et choix de recherches. Essai d'auto-socio-analyse (1973-1984) ». Cahiers « Jeunesses et Sociétés », 3-4-5 : 27-121. 
MENGER Pierre-Michel (2009). Le Travail créateur. S'accomplir dans l'incertain. Paris, Gallimard/Seuil, « Hautes études ».

MoRRISON Toni (1990). Playing in the Dark : Whiteness and The Literary Imagination. New York, Vintage Books.

MouLIN Raymonde (1971). "La Culture du pauvre. À propos du livre de Richard Hoggart ». Revue française de sociologie, 12(2) : 255-258.

Moulin Raymonde (1992). L'Artiste, l'institution et le marché. Paris, Flammarion.

MouLIN Raymonde (dir.) (1986). Sociologie de l'art. Paris, La Documentation française.

MoULIN Raymonde, PASSERON Jean-Claude, PASQUIER Dominique, PoRTO-

VAsquez Fernando (1985). Les Artistes, essai de morphologie sociale. Paris, La Documentation Française.

NAUDIER Delphine \& ROLLET Brigitte (2007). Genre et légitimité culturelle. Quelle reconnaissance pour les femmes ?. Paris, L'Harmattan.

NAVEL Georges (1945). Travaux. Paris, Gallimard.

NeVEU Érik (1999). "Pour en finir avec l'enfantisme. Retours sur enquêtes ". Réseaux, 92-93 : 175-201.

NEVEU Érik (2008). «Les voyages des cultural studies ». L'Homme, 187$188: 315-341$

NoIRIEL Gérard (1988). Le Creuset français. Histoire de l'immigration $\left(X I X^{e}-X X^{e}\right.$ siècle). Paris, Seuil.

Olivier DE SARDAN Jean-Pierre (2008). La Rigueur du qualitatif. Les contraintes empiriques de l'interprétation socio-anthropologique. Louvain, Bruylant Academia.

PARETo Vilfredo (1917). Traité de sociologie générale. Traduit de l'italien par Pierre Boven. Lausanne, Payot.

PASQUali Paul \& SchWARTZ Olivier (2016). "La Culture du pauvre : un classique revisité. Hoggart, Les classes populaires et la mobilité sociale ». Politix, 114 : 21-45.

Pasqual Paul (2014). Passer les frontières sociales. Comment les " filières d'élite " entrouvrent leurs portes. Paris, Fayard.

Pasquier Dominique (1989). La Culture des sentiments. L'expérience télévisuelle des adolescents. Paris, Éditions de la MSH.

PASquier Dominique (2005). " La "culture populaire" à l'épreuve des débats sociologiques ». Hermès, 42 : 60-69.
PASSERON Jean-Claude (2006) [1991]. Le Raisonnement sociologique. Un espace non poppérien de l'argumentation. Paris, Albin Michel, nouvelle édition revue et augmentée (première édition Paris, Nathan).

Passeron Jean-Claude \& Pedler Emmanuel (1991). Le Temps donné aux tableaux. Compte rendu d'une enquête au musée Granet. Marseille, Imerec.

PAsseron Jean-Claude \& Grumbach Michel (dir.) (1985). L'CEil à la page : enquête sur les images et les bibliothèques. Paris, Bibliothèque publique d'information, Service des études et de la recherche.

PAsSERON Jean-Claude (dir.) (1999). Richard Hoggart en France. Paris, Bibliothèque publique d'information.

Pedler Emmanuel (2010). « Les sociologies de la musique de Max Weber et Georg Simmel. Une théorie relationnelle des pratiques musiciennes ». L'Année sociologique, 60(2) : 305-330.

Pedler Emmanuel (2016). L'Esprit des lieux. Paris, Éditions de l'EHESS. Pedler Emmanuel \& Bourbonnaud David (2002a). "L'offre du festival "in" d'Avignon : effet d'imposition ou stimulation culturelle ? ». Actes du colloque d'Amiens.

Pedler Emmanuel \& Bourbonnaud David (2002b). « La programmation du Festival. Un pacte de confiance entre l'organisation festivalière et son public ». In ETHIS Emmanuel (dir.), Avignon : le public réinventé. Paris, La Documentation française : 131-159.

Pedler Emmanuel \& ZerbiB Olivier (2001). Les Nouvelles Technologies à l'épreuve des bibliothèques. Paris, Bibliothèque publique d'information. Peterson Richard A. \& Simkus Albert (1992). " How Musical Tastes Mark Occupational Status Groups ». In LAMONT Michèle \& FournIER Marcel, Cultivating differences : Symbolic Boundaries and the Making of Inequality. Chicago, The University of Chicago Press : 152-168.

Peterson Richard A. (1992). "Understanding audience segmentation : From elite and mass to omnivore and univore $»$. Poetics, 21(4) : 243-258. PETERSON Richard A. (1997). "The Rise and Fall of Highbrow Snobbery as a Status Marker ». Poetics, 25(2-3) : 75-92.

Peterson Richard A. \& Kern Roger M. (1996). "Changing Highbrow Taste : from Snob to Omnivore ». American Sociological Review, 61(5) : 900-907.

PUDAL Bernard (1991). « Le populaire à l'encan ». Politix, 13 : 53-64. 
RANCIÈRE Jacques (1981). La Nuit des prolétaires. Archives du rêve ouvrier. Paris, Fayard.

RANCIÈRE Jacques (2011). La Leçon d'Althusser. Paris, La Fabrique.

ReVEL Jacques (dir.) (1996). Jeux d'échelles. La micro-analyse à l'expérience. Paris, Gallimard/Seuil.

RoBInson Eric E. (1968). The New Polytechnics. The People's Universities. Harmondsworth, Penguin.

ROEDIGER David (1991). The Wages of Whiteness : Race and the Making of the American Working Class. New York, Verso.

SAPIRO Gisèle (2013a). "La carrière internationale de La Distinction ». In CoULANGEON Philippe \& DuvaL Julien (dir.), Trente ans après La Distinction de Pierre Bourdieu. Paris, La Découverte : 45-58.

SAPIRO Gisèle (2013b). "Le champ est-il national ? La théorie de la différenciation sociale au prisme de l'histoire globale ". Actes de la recherche en sciences sociales, $200: 70-85$.

SCHILLING Heinz (1981). Konfessionskonflikt und Staatsbildung. Eine Fallstudie über das Verhältnis von religiösem und sozialem Wandel in der Früh Neuzeit am Beispiel der Grafschaft Lippe. Gütersloh, Bertelsmann. ScotT James (2008). La Domination et les arts de la résistance. Fragments du discours subalterne. Traduction française par Olivier Ruchet. Paris, Éditions Amsterdam.

Servien Pius (1935). Principes d'esthétique. Problèmes d'art et langage des sciences. Paris, Boivin.

SINGLY François (DE) (1998). « Bourdieu : nom propre d'une entreprise collective ». Le Magazine littéraire, $369: 39-44$.

SUTTON-SMith Brian (1970). "Psychology of Childlore : The Triviality Barrier ». Western Folklore, 29(1): 1-8.

TAINE Hyppolite (1858). Essais de critique et d'histoire. Paris, Hachette. VEYNE Paul (1971). Comment on écrit l'histoire. Essai d'épistémologie. Paris, Seuil.

VEYNE Paul (2008). Foucault. Sa pensée, sa personne. Paris, Albin Michel. WEBER Max (1998) [1921]. Sociologie de la musique. Les fondements rationnels et sociaux de la musique [Die rationalen und soziologischen Grundlagen der Musik, Tübingen, Drei Masken Verlag]. Traduit de l'allemand par Jean Molino et Emmanuel Pedler. Paris, Métailié.
Wimmer Andreas \& GLICK SCHILLER Nina (2002). « Methodological Nationalism and Beyond : Nation-State Building, Migration and the Socia Sciences ». Global Network, 2 : 301-334. 